Revista de Economia Política, vol. 40, $n^{\circ}$ 1, pp. 138-160, janeiro-março/2020

\title{
Pobreza multidimensional no Brasil: uma análise do período 2004-2015
}

\author{
Multidimensional poverty in Brazil: \\ analysis of the period 2004-2015
}

\author{
JOSÉ JAIME DA SILVA*,** \\ MIGUEL ANTONIO PINHO BRUNO ${ }^{+}$ \\ DENISE BRITZ DO NASCIMENTO SILVA ${ }^{x}$
}

\begin{abstract}
RESUMO: Este artigo constrói um Índice de Pobreza Multidimensional (IPM) para o Brasil, utilizando informações da PNAD/IBGE e faz a análise de sua evolução no período 2004-2015. O IPM proposto foi adaptado daquele desenvolvido por Alkire e Santos (2013). Os resultados obtidos corroboram a redução da incidência da pobreza multidimensional no Brasil. Contudo, as pessoas saem da pobreza para a condição de vulnerabilidade, mostrando uma melhoria gradual das condições de vida da população. Regionalmente, houve redução da incidência da pobreza em todas as regiões, principalmente nas regiões Norte e Nordeste.
\end{abstract}

PALAVRAS-CHAVE: Pobreza multidimensional; capacidades; bem-estar; Pesquisa Nacional por Amostra de Domicílios.

ABSTRACT: The main goals of this paper were to construct a Multidimensional Poverty Index (MPI) for Brazil using data from PNAD and also provides an analysis of its evolution for the period 2004-2015. The proposed IPM follows the method developed by Alkire and Santos (2013). The results confirm the reduction on the incidence of multidimensional poverty in Brazil. However, people move out of poverty into the stage of vulnerability, show-

\footnotetext{
* Assistente de pesquisa do Instituto de Pesquisa Econômica Aplicada - Diretoria de Estudos e Políticas Regionais, Urbanas e Ambientais - IPEA/DIRUR, Rio de Janeiro/RJ, Brasil. E-mail: Jaime.silva@ipea. gov.br. Orcid: https://orcid.org/0000-0002-0039-4279.

** Mestre em estudos populacionais da Escola Nacional de Ciências Estatísticas - ENCE-IBGE.

+ Professor pesquisador do Programa de Pós-Graduação em População, Território e Estatísticas Públicas da Escola Nacional de Ciências Estatísticas do Instituto Brasileiro de Geografia e Estatística - ENCE-IBGE, Rio de Janeiro/RJ, Brasil. E-mail: Miguel.bruno@ibge.gov.br. Orcid: https://orcid.org/0000-00033049-2512.

x Professora pesquisadora do Programa de Pós-Graduação em População, Território e Estatísticas Públicas da Escola Nacional de Ciências Estatísticas do Instituto Brasileiro de Geografia e Estatística ENCE-IBGE, Rio de Janeiro/RJ, Brasil. E-mail: Denise.silva@ibge.gov.br. Orcid: https://orcid.org/00000002-5514-7558. Submetido: 7/Março/2018; Aprovado 25/Abril/2019.
} 
ing a gradual improvement on living conditions. Regionally, there was a reduction in the incidence of poverty in the whole country, and notably in the North and Northeast regions. KEYWORDS: Multidimensional poverty; capabilities; welfare; National Household Survey. JEL Classification: I32; I31; D31.

\section{INTRODUÇÃO}

Os contrastes e desigualdades de renda e de oportunidades da população brasileira no que concerne às condições de vida precárias tornam relevante o aprofundamento de estudos dos seus determinantes. Tais desigualdades podem ser entendidas pelo reconhecimento da história socioeconômica do Brasil. Segundo Gremaud (2006), a herança da escravidão no país e a situação precária dos escravos depois de libertos contribuem para explicar a distribuição desigual de renda e de oportunidades. Por outro lado, a distribuição de terras na colônia foi realizada em grandes latifúndios para poucas famílias e isto não mudou ao longo da história (Gremaud, 2006).

Segundo o relatório das Nações Unidas, as pessoas estão sujeitas a privações que vão muito além da renda e do consumo e essas outras privações podem ser parcialmente integradas no conceito de pobreza multidimensional (PNUD, 2014). O Banco Mundial também utiliza a linha de pobreza de U\$ 3,10 (em Paridade de Poder de Compra). A proporção de pobres vem diminuindo ao longo do tempo no mundo, com aceleração de queda a partir da década de 2000, levando ao cenário da década atual, no qual menos de $10 \%$ da população mundial vive em situação de pobreza de renda ${ }^{1}$. Dados de 2013 para o Brasil indicam que existiam, nesse ano, 18,5 milhões de pessoas vivendo com menos de \$3,10 (PPP) por $\mathrm{dia}^{2}$.

Estatísticas sobre pobreza no ano de 2014 (divulgados pelo IPEA - Instituto de Pesquisas Econômicas Aplicadas com base na PNAD/IBGE) revelam que existiam 9,9\% de domicílios com renda domiciliar per capita abaixo da linha de pobreza. O Índice de Gini, que mede o grau de desigualdade na distribuição da renda domiciliar per capita entre os indivíduos, tem diminuído ao longo dos anos no Brasil. No final da década de 1980, era de 0,63, e manteve-se estável até 1998, atingindo o valor de 0,51 em 2014. Vale lembrar que o Índice de Gini é calculado com a renda pessoal e, assim, não consegue captar a distribuição funcional da renda. A distribuição funcional da renda tem uma relação inversa com o Índice de Gini. Quando o salário mínimo real aumenta, a participação da remuneração do trabalho no PIB aumenta e o Índice de Gini diminui, expressando a melhora na

\footnotetext{
${ }^{1}$ Dados de 2013.

${ }^{2}$ Disponível em: http://povertydata.worldbank.org/poverty/country/BRA.
} 
distribuição pessoal da renda. Ao longo do período 1988-2014, algumas políticas de transferência de renda foram implementadas com sucesso na redução do déficit de renda da população-alvo. Segundo Rocha (2013), duas condições foram favoráveis para o sucesso dessas políticas: o Brasil precisa apresentar renda per capita razoável (12 mil dólares) e a dispor de boas estatísticas públicas.

O principal objetivo deste trabalho foi construir e calcular um Índice de Pobreza Multidimensional (IPM) para o Brasil, com base nos microdados da PNAD, adaptando a metodologia proposta em Alkire e SantoS (2013). Assim, o IPM proposto poderá servir para o acompanhamento anual da pobreza multidimensional no Brasil. As análises abrangem o período 2004-2015 e referem-se às grandes regiões do Brasil.

Este artigo é composto por quatro seções, além desta introdução. A primeira seção apresenta uma revisão histórica e teórica da origem das desigualdades, abordando as especificidades da pobreza e das formas utilizadas para medi-la. A segunda seção descreve o método adotado e a fonte de dados. A análise dos resultados compõe a terceira seção, que é seguida pelas considerações finais.

\section{BREVE HISTÓRICO DOS CONCEITOS DE POBREZA E DISCUSSÃO TEÓRICA}

\section{Origem histórica da pobreza no Brasil}

Segundo Furtado (2007), durante o ciclo da cana-de-açúcar, "pelo menos noventa por cento da renda" de origem do comércio de açúcar ficavam com os proprietários de engenho. Uma explicação plausível para que tal renda não tenha sido gasta na colônia é que parte desta renda pertencia a não residentes. Durante um século e meio (final do séc. XVII e o começo do séc. XIX), a renda real da população do Nordeste diminuiu. Nota-se que a economia do interior tinha uma tendência a se tornar uma economia de subsistência com a transferência da população da economia açucareira para a pecuária no período de depressão. O autor denomina o ocorrido como "lento processo de 'atrofiamento', no sentido de que a renda real per capita de sua população declinou secularmente" (Furtado, 2007, p. 104).

Furtado ainda defendeu a hipótese de que o crescimento demográfico durante este século e meio teria se intensificado devido às melhores condições de alimentação na região onde a pecuária era predominante (Nordeste não açucareiro). Ele aponta também que a economia nordestina involuiu. $\mathrm{O}$ setor açucareiro perdia importância e o pecuário diminuía a produtividade com o seu crescimento. A divisão do trabalho e a especialização também involuíram. A formação da população e da economia do Nordeste estavam ligadas à decadência da empresa açucareira (Furtado, 2007). Tal dinâmica populacional e econômica serviu de pano de fundo para o surgimento de altas taxas de pobreza na região Nordeste do Brasil, durante o século XX, e que perduram no início do século XXI.

Algumas diferenças entre a formação da economia cafeeira e as economias de 
subsistência são apontadas por Furtado: os dirigentes da economia cafeeira tinham experiência comercial e influíram na política econômica e financeira do Brasil. O poder político tende a se subordinar aos interesses do grupo econômico hegemônico e a proximidade com a capital ajudou a estabelecer essa subordinação (FURTADO, 2007).

Ao mesmo tempo em que o preço do café estava aumentando internacionalmente, surgiu a demanda por borracha que pôde ser aproveitada pelo Brasil. No entanto, com a proibição do tráfico negreiro, uma corrente migratória europeia foi a solução para a mão de obra cafeeira. Outro ponto a destacar foi a dificuldade de adaptação desta população às condições de trabalho nas grandes lavouras. Sendo assim, foi criado um conjunto de mecanismos para promover uma corrente migratória europeia para resolver o problema da mão de obra. Ao mesmo tempo, houve um incentivo de levar a população do Nordeste, especula-se 260 mil pessoas ${ }^{3}$, para a Amazônia para suprir a demanda de mão de obra na extração de borracha. Contudo, essa população acabou na miséria devido a uma combinação de dois fatores: $i$ ) as péssimas condições de alocação no trabalho, pois o trabalhador chegava endividado e acabava em um regime de servidão e ii) o preço internacional da borracha diminuiu no início do século XX. Com a solução mundial para o problema da baixa oferta de borracha, a população imigrante acabou na extrema miséria e com o passar do tempo assumiu formas primitivas de economia de subsistência. O nordestino levado para a Amazônia não tinha recursos para voltar (Furtado, 2007).

O autor não deixa de apontar que tais diferenças resultariam na prosperidade do Sudeste cafeeiro, com a imigração europeia e a manutenção do alto preço do café, enquanto a economia da borracha caía por terra, deixando sua população na extrema pobreza. Enquanto no Sudeste o escravo acabou indo para a economia de subsistência, no Nordeste alguns ficaram em engenhos como assalariados devido à economia de subsistência já ter se expandido para o interior. Ele aponta que o ex-escravo preferiu o ócio a trabalhar e, mesmo na região mais desenvolvida, a utilização da força de trabalho formada por ex-escravos reduziu-se. Vale lembrar que, no século XX, a economia cafeeira contribuiu para o desenvolvimento da indústria no Brasil. Segundo Furtado (2007), a crise de 1930 acelerou o processo de expansão da industrialização do país. A crise também impulsionou a importação de bens de capital. A ideia central da industrialização era criar uma oferta interna para suprir bens que eram importados, assim ficou conhecida como Industrialização por Substituição de Importações (ISI).

Segundo Silva (1996), antes das Leis de Terras as terras pertenciam à Coroa e eram concedidas para o uso dos grandes latifundiários, mas não poderiam ser vendidas. A Lei de Terras estabeleceu que a propriedade de terras fosse pela compra. Assim a lei favoreceu o empobrecimento da população pela dificuldade imposta ao acesso da terra e o aumento de preço da terra.

\footnotetext{
${ }^{3}$ Furtado, 2007, p. 192.
} 
Tais fatos mostram como a formação de economias de subsistência em algumas localidades, e também a condenação de parte da população à miséria (caso dos nordestinos que migraram para a Amazônia) bem como a desigualdade na distribuição de terras, resultaram em posteriores bolsões de pobreza que perduraram durante o século XX e início do $\mathrm{XXI}^{4}$. Esses ainda podem ser vistos nas estatísticas divulgadas nos censos do $\mathrm{IBGE}^{5}$.

\section{Da pobreza absoluta à pobreza multidimensional}

Ao longo da trajetória do pensamento científico sobre a pobreza, Codes (2008) aponta cinco concepções desenvolvidas durante o século XX: subsistência, necessidades básicas, privação relativa, privação de capacidades e pobreza multidimensional ${ }^{6}$. A concepção da subsistência nasce de pesquisas de nutricionistas ingleses que mostraram como a renda dos pobres não era suficiente para manutenção de seu rendimento físico no trabalho. Atualmente essa concepção é entendida como pobreza absoluta. No entanto, algumas críticas são feitas a essa abordagem. A primeira é que as pessoas não são apenas organismos individuais, mas seres sociais que necessitam existir de várias formas que vão além da existência física. Outra crítica é que o preço e a disponibilidade de alimentos variam ao longo do tempo e em diferentes sociedades (Codes, 2008).

A concepção das necessidades básicas inicialmente adotava mensurações que se baseavam na renda per capita ou no PIB. Depois passou a apontar para serviços como saneamento básico, água potável, educação, acesso à saúde etc. como forma de medir o atendimento das necessidades básicas de uma determinada população. Townsend (1993) apud Codes (2008) aponta que o entendimento da pobreza apenas como insuficiência de renda contribui para que o argumento simplista de que o crescimento econômico seja suficiente para combater a pobreza. A concepção da privação relativa enfoca a relação entre a privação e a estrutura social e institucional da sociedade. Neste caso, são considerados pobres aqueles que não têm os recursos suficientes para desempenhar os papéis que lhes são esperados. Sob esta perspectiva, pobreza e cidadania são questões intimamente ligadas, pois a pobreza é entendida como a manifestação da desigualdade própria da organização social (CODES, 2008) e impede a afirmação efetiva da cidadania plena e a consolidação de uma sociedade efetivamente democrática. Isso porque a democracia em sua

\footnotetext{
${ }^{4}$ Apesar de ter ocorrido uma redução da proporção de pobres em todas as regiões na década passada, os bolsões de pobreza que historicamente foram formados no Sertão nordestino e na região Norte continuam registrando proporções de pobres acima de $40 \%$. O número de municípios que apresentavam proporções de pobres acima de $60 \%$ reduziu e a concentração de municípios com baixa proporção de pobres está nas regiões Sul e Sudeste.

${ }^{5}$ Foi calculado o índice de Moran I para verificar a autocorrelação espacial e os dados do Censo 2010 apresentaram valor 0,78 para o conjunto de dados (estatisticamente significantes). Além disso, o Brasil apresentou dois grandes clusters de municípios com altas proporção de pobres.

${ }^{6}$ Esta concepção foi operacionalizada já no século XXI.
} 
dimensão política - governos instituídos com o voto popular - precisa ser completada com a democracia em sua dimensão econômica: acesso aos bens e serviços fundamentais a uma vida humana digna. Pressupondo, portanto, distribuição equitativa da renda e do estoque de riqueza.

Para Sen (2000), o fenômeno da pobreza deve ser apreendido pela ótica da privação de capacidades, pois engloba mais variáveis causais do que normalmente se supõe quando o avaliamos apenas pela ótica da renda. Por exemplo, são enfatizadas as capacidades que os indivíduos possuem, ou seja, a liberdade necessária para que a pessoa possa viver uma vida que ela valoriza. Apesar de haver diferenças entre pobreza de renda e pobreza de capacidades, as duas dimensões estão estruturalmente interligadas. No entanto, o autor aponta para uma taxa de conversão de renda em capacidades, que está sujeita a outras variáveis que dificultam as ações públicas para solucionar este problema. Existe, nesse sentido, uma dificuldade em operacionalizar o conceito de capacidade do indivíduo ${ }^{7}$.

Chega-se assim à perspectiva da pobreza multidimensional, que tenta abordar o problema em sua complexidade e interligação entre as causas e consequências que geram e reproduzem esse fenômeno social. O conceito de pobreza multidimensional tem origem nos estudos de Amartya Sen quanto à insuficiência da dimensão puramente financeira (fluxos de renda) para captar todas as privações. Vários autores defendem que essa abordagem pode concernir a diversos elementos que vão além da carência econômica, tais como saúde, educação, habitação, participação política, igualdade entre os sexos etc. (Codes, 2008). A importância deste conceito se apoia nos indicadores utilizados na construção do Índice de Pobreza Multidimensional e em algumas dimensões dos Objetivos do Desenvolvimento Sustentável (ODS).

Sen justifica a necessidade de se utilizar uma abordagem multidimensional da pobreza, pois as pessoas são atingidas por privações de maneiras diferentes. Então, o primeiro passo é reconhecer as várias dimensões às quais as pessoas estão sujeitas, e, em seguida, construir um indicador para mensurar a pobreza multidimensional. Para que essa abordagem possa ser operacionalizada, é preciso um método que incorpore as várias dimensões da vida das pessoas, promovendo maior validade e consistência ao indicador de pobreza e desigualdade social. Mestrum (2002) apud Codes (2008) aponta para duas dificuldades nesta abordagem multidimensional da pobreza. A primeira é que as diferentes dimensões não podem ser agregadas em um único indicador, por não se saber qual peso deve ser dado a cada dimensão. A segunda é que não se deve confundir as diferentes dimensões com a própria pobreza e deixar a renda em um último plano.

\footnotetext{
${ }^{7}$ Vale ressaltar que Sen desenvolve essa abordagem a partir dos "entitlements", ou seja, um conjunto de bens que uma pessoa pode obter utilizando os direitos e oportunidades que ela tem. Esses direitos estariam ligados aos Direitos Humanos.
} 


\section{Sobre as linhas de pobreza no Brasil}

Segundo Soares (2009), não existe um consenso sobre uma linha de pobreza oficial no Brasil. Isto explica o porquê de existirem tantos trabalhos que utilizam suas próprias linhas de pobreza e muitas vezes apresentando diferenças, sem razões específicas, da escolha de uma determinada linha de pobreza em detrimento de outras. A pergunta estritamente necessária, que determina o trabalho de construção e medição da pobreza, refere-se a sua definição conceitual. As diferentes definições levam a uma determinada linha de pobreza. Se a pobreza é considerada como um conceito complexo que não se resume à insuficiência de renda, então se deve utilizar um índice de pobreza que inclua dimensões não monetárias (escolha não muito utilizada no Brasil). Se o conceito de pobreza é associado a características nutricionais, considera-se o método das necessidades calóricas para a criação de uma linha de pobreza absoluta (normalmente monetária). A outra opção é compreender a pobreza como um conceito não absoluto, logo relativo. E, em seguida, observar se a renda per capita pode ser utilizada para medir a pobreza e compará-la com uma renda per capita de referência. Se a situação de pobreza for expressa por uma linha de pobreza que permita a implantação de uma política pública, neste caso existe uma linha de pobreza para servir de critério para inclusão no programa social (Soares, 2009).

Falcão e Costa (2014) fazem uma discussão sobre o estabelecimento de uma linha de pobreza para o Programa Brasil Sem Miséria. Segundo os autores, o desafio de estabelecer um conceito de pobreza a ser utilizado e a própria linha de pobreza passa por muitas escolhas que vão desde qual abordagem (definição do conceito) até como será medido (definição operacional). Após a escolha da abordagem, é necessário observar qual dimensão é mais importante e se realmente consegue medir a incidência de pobreza. Seguindo as recomendações do Compêndio sobre Melhores Práticas em Medição de Pobreza ${ }^{8}$, que indica linhas monetárias para países urbanizados em economia de mercado desenvolvidas, e outros estudos (Rocha, 2013), bem como parâmetros técnicos do Governo Federal, Falcão e Costa (2014) escolheram uma abordagem unidimensional e uma linha absoluta de pobreza. Assim, estabeleceram uma linha monetária de R $\$ 70,00$ para a extrema pobreza e R\$140,00 para pobreza.

\section{MATERIAIS E MÉTODO}

\section{Descrição do Método}

O Índice de Pobreza Multidimensional tem por objetivo quantificar a pobreza profunda, entendida como a incapacidade de uma pessoa ter, ao mesmo tempo, os

\footnotetext{
${ }^{8}$ Disponível em: https://ww2.ibge.gov.br/poverty/pdf/rio_group_compendium.pdf.
} 
indicadores satisfatórios de acordo com os Objetivos do Desenvolvimento do Milênio (ODM). O IPM é uma abordagem com o propósito de estabelecer uma medida comparável internacionalmente. Segundo as autoras Alkire e Santos (2013), o IPM baseia-se em uma família de medidas de pobreza desenvolvidas por Sabina Alkire e James Foster (2009) denominado Adjusted Headcount Ratio $\left(\mathrm{M}_{0}\right)$, que pertence a uma recente geração de medidas que renovaram o interesse no método direto de cálculo da pobreza. O IPM aplica o $\mathrm{M}_{0}$ para um conjunto de dez indicadores relacionados aos ODM, considerando três dimensões: saúde, educação e padrão de vida.

A construção do $\mathrm{M}_{0}$ começa com a definição dos indicadores. $\mathrm{M}_{0}$ é uma medida de pobreza composta por $d$ indicadores em uma população de $n$ indivíduos. Então, têm-se a matriz $n x d$ de capacidades $Y=\left[y_{i j}\right]$ para todos os $i$ indivíduos $(i=1,2,3, \ldots, n)$, nos $j$ indicadores $(j=1,2,3, \ldots, d)$. Cada linha da matriz mostra as capacitações daquele indivíduo $i$ nos vários indicadores. Cada coluna evidencia a distribuição do indicador $j$ nos vários indivíduos. $\mathrm{O}$ método $\mathrm{M}_{0}$ permite atribuir pesos diferentes para cada indicador. Define-se o vetor $w$ que inclui os pesos para cada indicador. Vale ressaltar que o somatório dos pesos é igual ao número de indicadores, tal que:

$$
\sum_{j=1}^{d} w_{j}=d
$$

O segundo passo é identificar os indivíduos em situação de pobreza na população, utilizando um procedimento em duas etapas. Um ponto de corte para cada dimensão é estabelecido por meio do vetor $z$. A partir dá, é definida a matriz de privações $G=\left[g_{i j}\right]$, cujos elementos assumem o valor do peso $w_{\mathrm{j}}$ quando $y_{\mathrm{ij}}<z_{\mathrm{j}}$, e zero quando $y_{i j} \geq z_{\mathrm{j}}$. Em outras palavras, as entradas individuais da matriz são equivalentes ao peso do indicador $\left(w_{\mathrm{j}}\right)$ quando a pessoa $i$ sofre privação do indicador $j$, e assume valor zero quando a pessoa não sofre privação naquele indicador.

A partir da matriz G, é definido o vetor coluna $c$ (deprivation scores), que na $i$-ésima linha assume o valor dado por:

$$
c_{i}=\sum_{j=1}^{d} g_{i j}
$$

Este valor representa a soma das privações sofridas pelo individuo $i$. Por último, é aplicado um ponto de corte no vetor de privações $c$ no qual o indivíduo é identificado como pobre, quando o escore de privações é maior ou igual ao segundo ponto de corte $k$ [33,33\%] (Alkire e Santos, 2010). No IPM proposto por Alkire e Santos (2013), as dimensões e indicadores são definidos como na Figura 1, abaixo. 


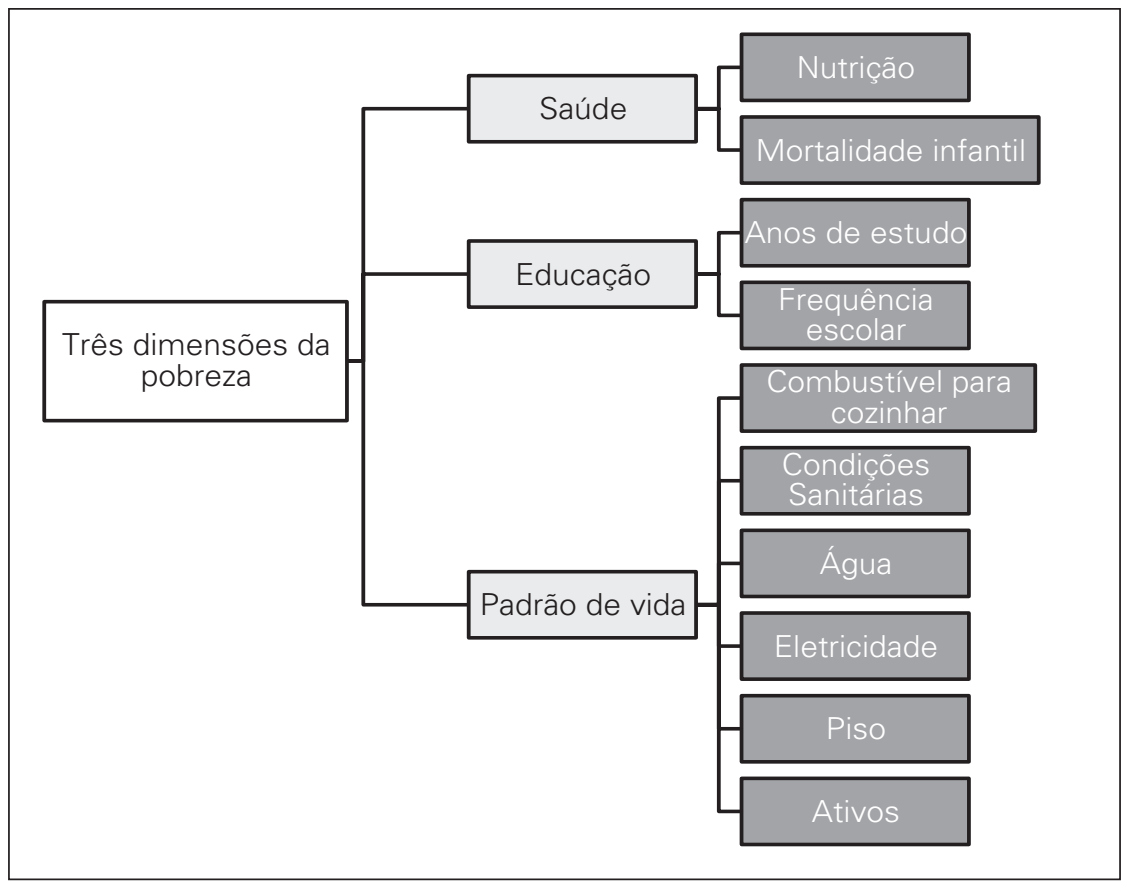

Fonte: Alkire e Santos (2013).

Dimensões, indicadores e a unidade de análise

O método utiliza uma linha de corte dupla: uma linha de corte em cada indicador, para identificar se o indivíduo sofre privação num dado indicador; e outra linha de corte do nível de pobreza. O nível de pobreza é calculado através da soma dos indicadores (multiplicada pelos seus respectivos pesos) obtendo o nível $c$ de privação do domicílio. Então, um ponto de corte de $33,3 \%$ ou maior é utilizado para indicar a ocorrência de situação de pobreza. Se esta pontuação é igual ou maior que $33,3 \%$, o domicílio e todos que nele residem são considerados pobres. Domicílios com pontuação igual ou maior que $20 \%$ e menor que $33,3 \%$ são considerados vulneráveis à pobreza multidimensional, e domicílios com pontuação maior que $50 \%$ são considerados severamente pobres. A proporção de pessoas multidimensionalmente pobres é dada por:

$$
H=\frac{q}{n}
$$

onde $q$ é o número de pessoas multidimensionalmente pobres e $n$ o tamanho da população. A intensidade da pobreza $A$ estima a proporção de indicadores em 
que, em média, as pessoas pobres sofrem privação. A intensidade da pobreza é calculada apenas para as pessoas em situação de pobreza:

$$
A=\frac{\sum_{i}^{q} c_{i}}{q}
$$

onde $c_{i}$ é a pontuação de privação do $i$-ésimo indivíduo pobre. A pontuação de privação do $i$-ésimo indivíduo pobre pode ser expressa pelas privações em cada dimensão. Então, o IPM (Índice de Pobreza Multidimensional) é o valor do produto das duas medidas: proporção de pessoas multidimensionalmente pobres e intensidade da pobreza.

$$
I P M=H \cdot A
$$

\section{Adaptação para o caso brasileiro}

O presente trabalho propõe um indicador escalar de pobreza multidimensional (IPM), construído a partir de microdados disponíveis na Pesquisa Nacional por Amostra de Domicílios (PNAD), entre 2004 e 2015. Estes dados permitem estimar a intensidade e incidência da pobreza multidimensional, bem como o IPM, em si e o seu comportamento no período estudado. A forma de calcular o IPM (Índice de Pobreza Multidimensional) segue as recomendações do PNUD e a metodologia de Alkire e Santos (2013) descrita na seção anterior.

A base de dados foi construída objetivando a construção de um índice de pobreza multidimensional; esta base foi elaborada a partir dos microdados da PNAD. Em função das características de construção dos indicadores, a unidade mínima de análise escolhida foi o domicílio. Segundo o IBGE (2016), o domicílio é o local independente que serve como moradia e tem um ou mais cômodos. Vale ressaltar que foi levado em consideração o plano amostral da PNAD no cálculo das estimativas e seus ICs (Intervalos de Confiança) ${ }^{9}$.

\section{Dimensões, indicadores e pontos de corte}

Dado que a incorporação de dimensões no IPM está condicionada aos dados disponibilizados na PNAD ${ }^{10}$, foi necessário ajustar escolhas de dimensões e alguns indicadores, buscando sempre medir os funcionamentos básicos alcançados pelas pessoas. Logo, a dimensão saúde (não investigada na PNAD) foi substituída pela dimensão capacidade econômica. As dimensões escolhidas são educação, padrão

\footnotetext{
${ }^{9}$ Para detalhes sobre a precisão das estimativas e o método de estimação, ver Silva, 2016.

${ }^{10}$ A PNAD é uma pesquisa amostral realizada por meio de um processo de amostragem probabilística em três estágios. Para elaboração deste trabalho, o plano amostral bem como os pesos da PNAD foram incorporados em todo o processo de elaboração do IPM, seguindo orientação e utilizando procedimentos elaborados por Djalma e Damico (2016) para a PNAD. Tais procedimentos estão disponíveis em http:// www.asdfree.com/ e na comunidade Github no endereço: https://github.com/ajdamico/asdfree.
} 
de vida e a capacidade econômica (uma medida da capacidade de uma pessoa conseguir emprego e renda na sociedade ${ }^{11}$.

A dimensão padrão de vida tem cinco indicadores: acesso à água tratada, condições sanitárias, destino do lixo, iluminação e ativos. O indicador chamado de ativos refere-se à propriedade de alguns bens duráveis, acesso à informação e bem-estar. A dimensão educação possui dois indicadores que registram se a pessoa de referência do domićlio cursou pelo menos ensino médio completo e se todos os moradores com dez anos ou mais sabem ler. A dimensão capacidade econômica tem três indicadores: se a pessoa de referência trabalha (ou trabalhou) ou se é aposentado/pensionista, renda real domiciliar per capita e se o domicílio é próprio ou não. Para cada indicador foi elaborada uma árvore de decisão de acordo com a lógica sequencial que o entrevistador segue durante a entrevista.

A dimensão padrão de vida procura descrever o quanto as condições de vida e bens de consumo da população podem ser importantes para determinar a pobreza. Então, nesta dimensão, foi considerado o acesso à água limpa, condições sanitárias, destinação do lixo, tipo de iluminação e ativos. Todos os indicadores tiveram um ponto de corte específico que aponta uma situação como adequada ou não adequada, sendo que, quando a situação está adequada, aquele indicador ajuda a reduzir a pobreza multidimensional do domićlio e, quando a situação está inadequada, aquele indicador ajuda a aumentar a pobreza multidimensional do domicílio. O ponto de corte, escolha das variáveis e sua forma de cálculo seguiram as recomendações de Alkire e Santos (2013).

A dimensão educação procura avaliar o grau de escolaridade dos integrantes do domicílio e indica as capacidades educacionais dos indivíduos. A educação além de um determinado nível (ensino médio) aumenta a capacidade de conseguir emprego ou um emprego mais qualificado que amplie sua renda. Logo, auxilia na ampliação de capacidades em geral (Sen, 2000). Esta dimensão tem dois indicadores: se a pessoa de referência tem ensino médio completo e se todas as pessoas com dez anos ou mais sabem ler e escrever.

A dimensão capacidade econômica tem por objetivo sintetizar a capacidade de obter emprego e renda, bem como fornece uma medida de propriedade das famílias. Esta dimensão possui três indicadores: emprego, renda domiciliar per capita e uma proxy de propriedade de imóvel. Apesar do conceito de pobreza multidimensional não utilizar a renda como principal indicador da situação de pobreza, a renda será utilizada como um dos indicadores desta dimensão pela sua importância para as pessoas aumentarem suas capacidades. A renda domiciliar per capita foi calculada em valores de 2015, ou seja, valores reais ${ }^{12}$. O IBGE pu-

\footnotetext{
${ }^{11}$ Vaz, (2013) faz uma análise sobre as variáveis socioeconômicas e de renda que devem ser utilizadas para estimar, por análise fatorial, domicílios em condição de extrema pobreza. Os pontos de corte para as variáveis utilizadas por Vaz (2013) serviram de inspiração para estabelecer os pontos de corte do presente trabalho.

12 Este indicador é calculado deflacionando-se os valores do rendimento mensal para os valores atuais (foram utilizados os valores de 2015 como base) e é comparado com meio salário mínimo real per capita.
} 
blica o rendimento domiciliar per capita depois de feita a devida imputação de dados faltantes. O Quadro 1 abaixo descreve os indicadores, seus pesos relativos e as dimensões do IPM proposto.

Quadro 1: Dimensões, Indicadores e Pesos do IPM

\begin{tabular}{|c|c|c|c|}
\hline \multicolumn{2}{|l|}{ Dimensão } & \multicolumn{2}{|l|}{ Indicador } \\
\hline Nome & Peso & Nome & Peso relativo \\
\hline \multirow{5}{*}{ Padrão de vida } & \multirow{5}{*}{$1 / 3$} & Acesso a água limpa & $1 / 10$ \\
\hline & & Condições sanitárias & $1 / 10$ \\
\hline & & Destinação do Lixo & $1 / 10$ \\
\hline & & Iluminação & $1 / 10$ \\
\hline & & Ativos $^{13}$ & $1 / 10$ \\
\hline \multirow[b]{2}{*}{ Educação } & \multirow[b]{2}{*}{$1 / 3$} & Anos de estudo da pessoa de referência & $1 / 10$ \\
\hline & & $\begin{array}{l}\text { Se todas as pessoas (com } 10 \text { anos } \\
\text { ou mais) sabem ler e escrever }\end{array}$ & $1 / 10$ \\
\hline \multirow{3}{*}{ Capacidade Econômica } & \multirow{3}{*}{$1 / 3$} & Emprego da pessoa de referência & $1 / 10$ \\
\hline & & Renda per capita & $1 / 10$ \\
\hline & & Indicador de propriedade & $1 / 10$ \\
\hline
\end{tabular}

Fonte: PNAD (IBGE).

\section{ANÁLISE DOS RESULTADOS}

\section{Pobreza Multidimensional no Brasil}

A incidência da pobreza $(\mathrm{H})$, é a proporção de pessoas que ficam abaixo do ponto de corte de pobreza multidimensional, ou seja, tem uma interpretação semelhante à da proporção de pobres associada aos indicadores de pobreza de renda. $\mathrm{Na}$ análise a seguir, esta incidência é denominada como proporção de pobres. Os resultados preliminares apontam uma redução do Índice de Pobreza Multidimensional de 2004 a 2015, como pode ser observada na Tabela 1. Em nível nacional, o IPM saiu de 0,16 no ano de 2004 para 0,09 em 2015 e, neste mesmo período, a população abaixo da linha de pobreza multidimensional apresentou uma redução de $27 \%$ para $16 \%$.

Esta linha de pobreza é utilizada para inclusão no Cadastro Único dos Programas Sociais do Governo Federal, na forma de valores monetários (Falcão e Costa, 2014).

${ }^{13}$ Os ativos são uma combinação de vários bens de consumo duráveis: celular, fogão, televisão, geladeira, máquina de lavar roupa e acesso a TIC (tecnologias da informação e comunicação). 
Tabela 1: Índice de Pobreza Multidimensional - Brasil - 2004-2015

\begin{tabular}{cccc}
\hline Ano $^{14}$ & $\begin{array}{c}\mathrm{H} \\
(\%)\end{array}$ & $\begin{array}{c}\text { Pobres } \\
\left(\mathrm{N}^{\circ} \text { pessoas }\right)\end{array}$ & IPM \\
\hline 2004 & $27,1 \%$ & 45.141 .907 & 0,164 \\
2005 & $25,8 \%$ & 43.835 .592 & 0,157 \\
2006 & $24,7 \%$ & 42.596 .459 & 0,149 \\
2007 & $23,3 \%$ & 40.680 .803 & 0,139 \\
2008 & $21,6 \%$ & 38.284 .715 & 0,127 \\
2009 & $21,3 \%$ & 37.760 .525 & 0,124 \\
2011 & $18,6 \%$ & 33.580 .342 & 0,107 \\
2012 & $18,4 \%$ & 34.082 .919 & 0,104 \\
2013 & $17,9 \%$ & 33.208 .024 & 0,102 \\
2014 & $16,8 \%$ & 31.998 .768 & 0,093 \\
2015 & $16,9 \%$ & 32.947 .355 & 0,094 \\
\hline
\end{tabular}

Fonte: IBGE, Microdados da PNAD 2004-201514.

Em termos absolutos, houve uma redução de mais de 12 milhões de pessoas abaixo da linha da pobreza multidimensional (ou uma redução de $37 \%$ ), ou seja, em 2015 havia 12 milhões de pessoas a menos abaixo da linha da pobreza multidimensional em comparação com 2004. O IPM teve uma redução de mais de $70 \%$ no mesmo período e a população brasileira apresentou um crescimento de $11 \%$. Em termos de visualização da variação do IPM no período o índice de variação com base no ano de 2004 mostra que o decrescimento foi de mais de $40 \%$.

A população vulnerável à pobreza multidimensional teve uma pequena redução durante o período estudado (2004 a 2015), saindo de 36\% em 2004 para 35,5\% em 2015. Apesar de ser uma redução pequena em termos percentuais, em termos absolutos houve um aumento de 9 milhões de pessoas vulneráveis à pobreza multidimensional. Ao longo dos anos, houve uma redução menor em todos estes indicadores em 2009 e um aumento no ano de 2011 que podem ser efeitos da crise financeira de 2008.

Entre a população abaixo da linha da pobreza, pode-se observar um subgrupo da proporção da população em pobreza severa. A população em situação de pobreza severa saiu de 15\% em 2004 para 8\% em 2015. Em termos absolutos, foi uma redução de aproximadamente 9 milhões (ou $53 \%$ ) da população em situação de pobreza severa. Contudo, dos 32 milhões abaixo da linha de pobreza multidimensional, 17 milhões ainda estão sob pobreza severa, ou seja, $53 \%$ da população pobre sofre de privações em, pelo menos, metade dos indicadores.

${ }^{14}$ No ano do Censo Demográfico não há PNAD. 
Tabela 2: População Vulnerável e Pobreza Severa - Brasil - 2004-2015

\begin{tabular}{|c|c|c|c|c|}
\hline Ano & $\begin{array}{c}\text { População } \\
\text { vulnerável } \\
(\%)\end{array}$ & $\begin{array}{c}\text { População } \\
\text { vulnerável } \\
\text { ( } \mathrm{N}^{\circ} \text { pessoas) }\end{array}$ & $\begin{array}{c}\text { Pobreza } \\
\text { severa } \\
(\%)\end{array}$ & $\begin{array}{c}\text { Pobreza } \\
\text { severa } \\
\left(\mathrm{N}^{\circ} \text { pessoas }\right)\end{array}$ \\
\hline 2004 & $36,0 \%$ & 59.892 .912 & $15,8 \%$ & 26.339 .037 \\
\hline 2005 & $36,3 \%$ & 61.711 .644 & $14,9 \%$ & 25.277 .945 \\
\hline 2006 & $36,6 \%$ & 62.933 .256 & $14,1 \%$ & 24.362 .364 \\
\hline 2007 & $35,8 \%$ & 62.342 .862 & $13,3 \%$ & 23.179 .212 \\
\hline 2008 & $36,0 \%$ & 63.619 .179 & $12,1 \%$ & 21.507 .531 \\
\hline 2009 & $36,5 \%$ & 64.654 .937 & $11,8 \%$ & 20.873 .660 \\
\hline 2011 & $36,3 \%$ & 65.326 .297 & $10,0 \%$ & 18.136 .478 \\
\hline 2012 & $35,7 \%$ & 66.018 .070 & $9,7 \%$ & 18.099 .476 \\
\hline 2013 & $35,9 \%$ & 66.442 .499 & $9,4 \%$ & 17.546 .939 \\
\hline 2014 & $36,2 \%$ & 68.786 .289 & $8,6 \%$ & 16.418 .695 \\
\hline 2015 & $35,5 \%$ & 69.207 .897 & $8,8 \%$ & 17.175 .768 \\
\hline
\end{tabular}

Fonte: IBGE, Microdados da PNAD 2004-2015.

\section{Pobreza multidimensional por grandes regiões}

Fazendo uma leitura geral é possível afirmar que as regiões Norte e Nordeste apresentam os maiores índices de pobreza do ponto de vista da renda. Os resultados que seguem sobre a pobreza multidimensional, sua incidência e intensidade exibem uma distribuição semelhante (Gráfico 1). As regiões Norte e Nordeste apresentaram as maiores proporções de pobres, e a menor proporção, como esperado, foi registrada na região Sudeste. A intensidade da pobreza é maior na região Nordeste e menor na região Sul e o IPM apresenta seu valor máximo na região Norte e mínimo na região Sul. A seguir, segue a análise por região.

A Região Norte saiu de uma proporção de pobres de 51\% em 2004 para 34\% em 2015, o que resulta em uma redução de 50\%. A região Sudeste apresenta os resultados positivos para a maioria dos indicadores, saindo de uma proporção de pobres de 13\% em 2004 para 7\% em 2015. As maiores reduções foram das regiões Sul e Centro-Oeste e a menor redução foi na região Norte. 
Gráfico 1: Proporção de pobres $(H)$ - por regiões - 2004-2015

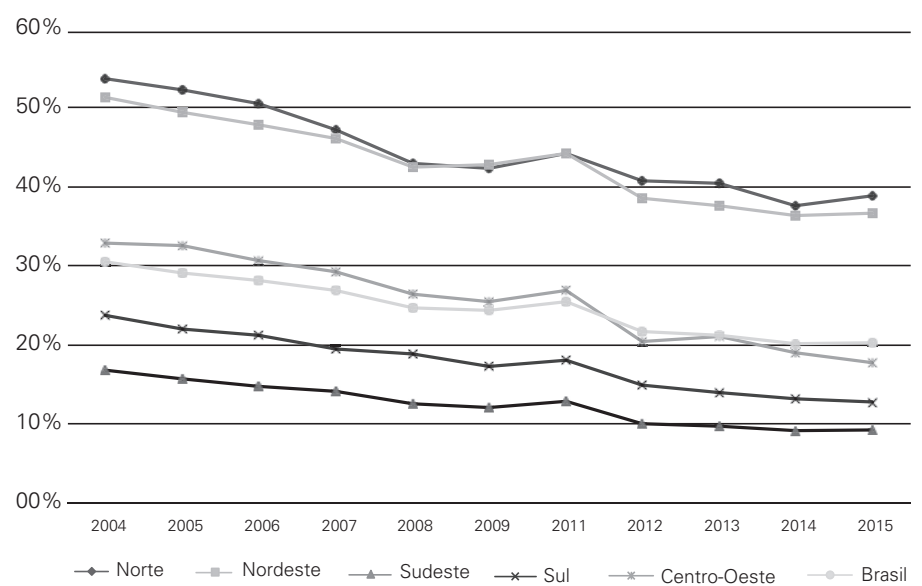

Fonte: IBGE, Microdados da PNAD 2004-2015.

Tabela 3: Razão de incidência da Pobreza Multidimensional - 2004-2015

\begin{tabular}{ccccc}
\hline Ano/região & Norte & Nordeste & Sul & Centro-Oeste \\
\hline 2004 & 3.76 & 3.49 & 1.49 & 2.18 \\
2005 & 3.88 & 3.49 & 1.50 & 2.27 \\
2006 & 3.99 & 3.66 & 1.53 & 2.28 \\
2007 & 4.02 & 3.74 & 1.49 & 2.33 \\
2008 & 3.97 & 3.82 & 1.53 & 2.28 \\
2009 & 4.16 & 4.10 & 1.54 & 2.63 \\
2011 & 4.54 & 4.04 & 1.53 & 2.07 \\
2012 & 4.63 & 4.25 & 1.50 & 2.14 \\
2013 & 4.78 & 4.34 & 1.41 & 2.30 \\
2014 & 4.73 & 4.39 & 1.42 & 2.15 \\
2015 & 4.85 & 4.46 & 1.35 & 2.03 \\
\hline
\end{tabular}

Fonte: IBGE, Microdados da PNAD 2004-2015.

Em termos de comparação entre as regiões, a Tabela 3 apresenta a razão da incidência da pobreza entre as regiões e a região Sudeste para destacar os diferenciais regionais bem como seu comportamento ao longo do tempo. É possível observar que as regiões Norte e Nordeste aumentaram a distância da incidência de pobreza observada em relação à região Sudeste. No entanto, as regiões Sul e 
Centro-Oeste apresentaram uma diminuição residual da distância em relação à região Sudeste, sendo difícil afirmar que houve alguma mudança significativa devido à natureza amostral da PNAD. Ou seja, apesar de ter apresentado uma redução do indicador em todas as regiões, a região Sudeste continua avançando mais na área social em comparação com Norte e Nordeste.

Gráfico 2: Proporção da população vulnerável à Pobreza Multidimensional - 2004-2015

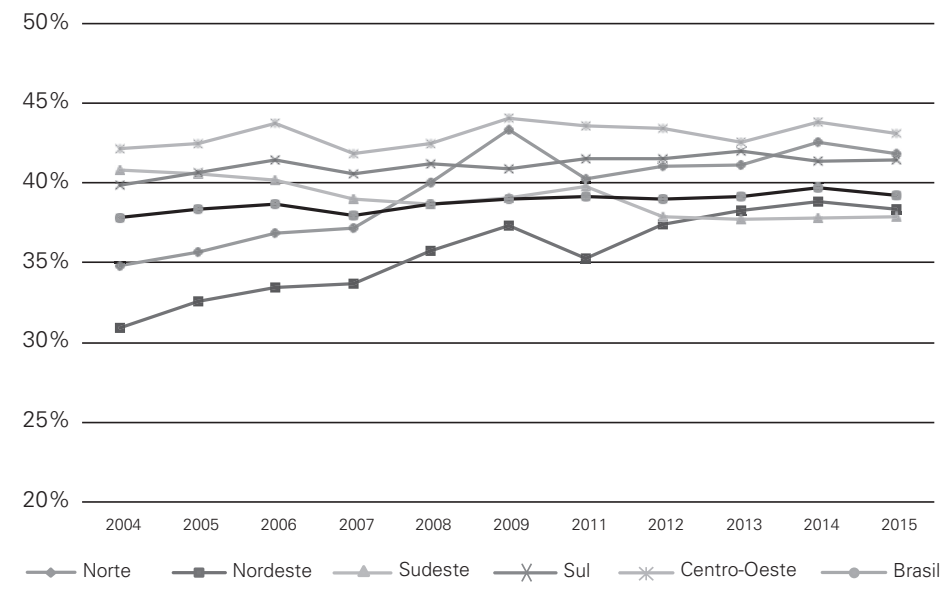

Fonte: IBGE, Microdados da PNAD 2004-2015.

Por outro lado, vale destacar que a população vulnerável à pobreza multidimensional aumentou no mesmo período nas regiões Norte e Nordeste. Apesar de o maior aumento ter ocorrido na região Nordeste, a população vulnerável à pobreza multidimensional em termos absolutos é maior na região Centro-Oeste. Em algumas regiões houve uma dinâmica inversa onde a incidência da pobreza apresenta uma redução e a população vulnerável à pobreza apresenta um aumento no mesmo período. Logo, pode-se apresentar a hipótese de que a população que sai da pobreza multidimensional vai para a situação de vulnerabilidade à pobreza.

A intensidade da pobreza apresentou uma pequena redução no período estudado em todas as regiões. Permaneceu em um valor aproximado de $50 \%$ nas regiões Norte e Nordeste e de $48 \%$ nas outras regiões. Este indicador mostra que a situação em termos de privação sofrida pelas pessoas que continuam abaixo da linha de pobreza multidimensional teve mudanças estatisticamente significativas ao longo do período estudado, apesar da mudança ter sido marginal. Este resultado mostra que a população pobre ainda sofre de muitas carências passíveis de serem resolvidas. 
Tabela 4: Índice de Pobreza Multidimensional (IPM) - Regiões - 2004-2015

\begin{tabular}{ccccccc}
\hline Ano & Norte & Nordeste & Sudeste & Sul & Centro-oeste & Brasil \\
\hline 2004 & 0,268 & 0,243 & 0,066 & 0,099 & 0,146 & 0,164 \\
2005 & 0,259 & 0,227 & 0,062 & 0,094 & 0,142 & 0,157 \\
2006 & 0,247 & 0,220 & 0,057 & 0,088 & 0,133 & 0,149 \\
2007 & 0,227 & 0,211 & 0,053 & 0,078 & 0,125 & 0,139 \\
2008 & 0,205 & 0,194 & 0,049 & 0,073 & 0,111 & 0,127 \\
2009 & 0,196 & 0,194 & 0,045 & 0,069 & 0,118 & 0,124 \\
2011 & 0,190 & 0,166 & 0,040 & 0,059 & 0,081 & 0,107 \\
2012 & 0,185 & 0,194 & 0,048 & 0,069 & 0,097 & 0,104 \\
2013 & 0,203 & 0,166 & 0,038 & 0,053 & 0,080 & 0,102 \\
2014 & 0,180 & 0,161 & 0,036 & 0,049 & 0,082 & 0,093 \\
2015 & 0,168 & 0,155 & 0,033 & 0,044 & 0,068 & 0,094 \\
\hline
\end{tabular}

Fonte: IBGE, Microdados da PNAD 2004-2015.

Em relação ao IPM, a redução nas regiões Norte e Nordeste foi expressiva por sair de um valor considerado alto em comparação a outras regiões. $\mathrm{Na}$ região Sudeste o IPM teve uma redução pela metade. O IPM saiu de 0,06 no ano de 2004 para 0,03 no ano de 2015. O melhor resultado foi na região Sul, que já apresentava um valor baixo, e saiu de 0,09 no ano de 2004 para 0,04 no ano de 2015. Foram calculados intervalos de confiança que podem mostrar que os indicadores obtiveram uma mudança estatisticamente significativa por não apresentarem interseção nos intervalos de confiança das estimativas entre os anos iniciais e os anos finais do período estudado. No Gráfico 3 pode ser observada essa mudança nos estimadores das grandes regiões, bem como os intervalos de confiança para os anos de 2005 e 2015 (por uma questão de estética não serão apresentados todos os anos).

As regiões Norte e Nordeste historicamente formaram economias que produzem uma dinâmica com grande tendência a bolsões de pobreza e uma parcela considerável da população em condições de vida abaixo do básico para ter uma vida digna. Este histórico foi apresentado na primeira seção e os resultados deste trabalho apontam que estes problemas estruturais se tornaram desafios para as políticas sociais.

Outro resultado importante é a incidência de pobreza severa. Neste caso, os domicílios apresentam privação em pelo menos 50\% dos indicadores. Apesar da grande redução deste fenômeno nas regiões Norte e Nordeste, ainda existe uma 
Gráfico 3: Índice de Pobreza Multidimensional (IPM) - Estimativas

e intervalos de confiança - Regiões - 2005-2015

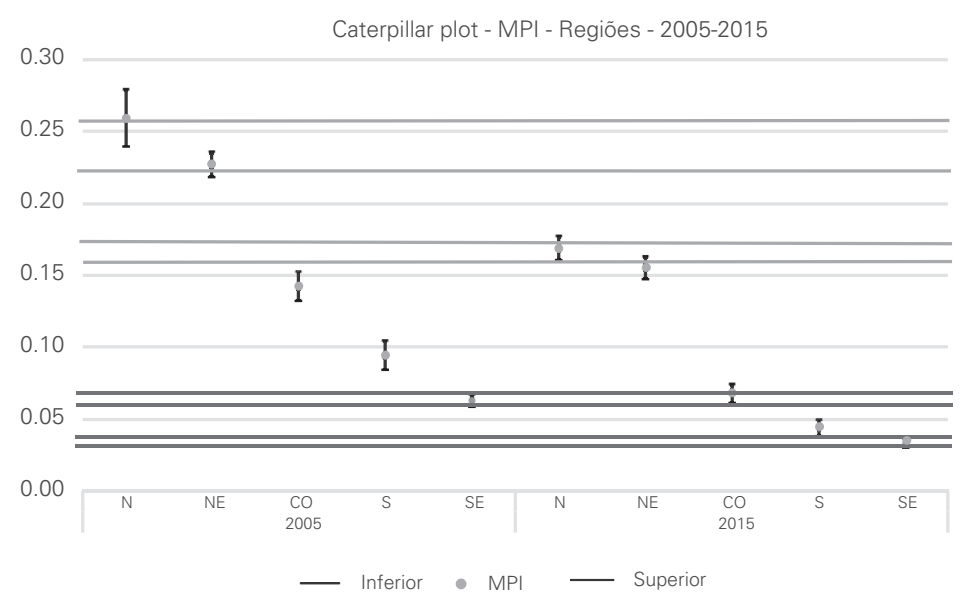

Fonte: IBGE, Microdados da PNAD 2005-2015.

grande parcela da população sofrendo pobreza severa. O movimento já citado aconteceu em todas as regiões: redução da pobreza severa e proporção de pobres e aumento da população vulnerável à pobreza ao mesmo tempo. O melhor resultado foi observado na região Sul, onde a pobreza severa saiu de 10\% em 2004 para $4 \%$ em 2015. A redução da pobreza severa nesta região foi na mesma proporção da redução do IPM e a população vulnerável à pobreza aumentou ligeiramente entre 2004 e 2015.

Apesar da redução do IPM em todas as regiões, vale ressaltar a contribuição de cada dimensão para o IPM que mostra de forma detalhada a dinâmica da melhoria das condições sociais em cada região ao longo dos onze anos estudados. $\mathrm{O}$ Índice de Pobreza Multidimensional apresentou valores mais altos para as regiões Norte e Nordeste, apesar das reduções que obtiveram durante o período estudado. Os menores valores apresentados do IPM estavam nas regiões Sul e Sudeste. As dimensões apresentaram alguma contribuição para a formação do IPM. Nas regiões Norte, Nordeste e Centro-Oeste, a maior contribuição era da dimensão padrão de vida. Tal resultado pode ser devido à menor taxa urbanização destas regiões. Na região Sudeste, a maior contribuição para o IPM fica por conta da dimensão educação. O IPM aparenta ser mais sensível a mudanças macroeconômicas como a crises e mudanças no salário real da população. A região Sul tem uma contribuição quase igualitária das dimensões.

Com relação à análise em cada dimensão, ou seja, no que diz respeito à proporção da população privada referente a cada indicador ao longo do período estudado, todos os indicadores apresentaram melhorias ao longo do período estudado na maioria das regiões. Vale destacar a dimensão capacidade econômica onde 
pôde-se observar que a partir de 2009 o indicador de emprego apresentou aumentos consistentes. Os indicadores de renda apresentaram redução da população em situação inadequada deste indicador em todas as regiões (excerto Norte) e as políticas de aumento real do salário mínimo e programas de transferência de renda podem ajudar a explicar tais resultados.

Saboia (2016) realizou um estudo com relação aos efeitos do rendimento sobre indicadores sociais como pobreza e desigualdade. $\mathrm{O}$ autor aponta que a elasticidade dos rendimentos dos trabalhadores que têm os menores níveis salariais é unitária ou elástica para a maioria das categorias. $\mathrm{O}$ autor testou os efeitos do salário mínimo sobre distribuição do rendimento pessoal e, de acordo com simulações, o aumento do salário mínimo foi responsável por $48 \%$ da redução da desigualdade de renda (Saboia e Hallak Neto, 2016). O autor também aponta para os efeitos do aumento do salário mínimo sobre a participação da remuneração dos empregados no PIB (massa salarial). O aumento do salário mínimo contribuiu para o aumento da participação das remunerações dos empregados no PIB. Segundo Saboia (2016) tanto o aumento dos postos de trabalho quanto o aumento da renda média explicam esta elevação no peso das remunerações na distribuição funcional da renda (Saboia e Hallak Neto, 2016).

Apesar da redução da proporção de pobres, a intensidade da pobreza teve uma redução muito pequena. Logo, a redução da pobreza foi voltada para aqueles mais próximos das linhas de pobreza de renda deixando aqueles abaixo da linha de pobreza multidimensional ainda privados de aproximadamente metade dos indicadores. Tal resultado é importante, dado que a pobreza multidimensional demanda políticas públicas que vão além de transferências de renda. A redução da incidência da pobreza multidimensional está associada a políticas de melhorias estruturais na economia que historicamente é deixada em segundo plano.

As maiores reduções do IPM foram nas regiões Sul e Centro-Oeste e a menor foi na região Norte. O IPM teve uma redução que desacelerou a partir de $2012 \mathrm{e}$ até aumentou na região Centro-Oeste entre 2012 e 2013. E nas regiões Norte e Nordeste aumentou em 2015 e não apresentou grandes variações entre 2014 e 2015 na região Sudeste. O IPM mostra-se mais sensível a mudanças macroeconômicas como a crise no início da década de 2010 no Brasil (com desaceleração da taxa de crescimento do PIB e o decrescimento deste a partir do segundo trimestre de 2014). A crise financeira de 2008 pode explicar o aumento da incidência da pobreza entre 2009 e 2011. Vale ressaltar que as políticas de aumento real do salário mínimo e o aumento do emprego formal contribuem consideravelmente para a redução do IPM durante a década de 2000, bem como mostra que o aumento do desemprego a partir de 2013 contribui para aumentar o IPM. 


\section{Comparação da Proporção de Pobres}

Em termos de comparação, o Gráfico 4 apresenta medidas de pobreza de renda do Banco Mundial e uma medida de pobreza absoluta (também utilizando o conceito de renda) disponibilizada pelo IPEA ${ }^{15}$. É possível observar a redução da incidência da pobreza em todas as medidas apresentadas no gráfico 3.4. No entanto, a incidência da pobreza evidenciada pelo IPM é superior às apresentadas pelos indicadores que utilizam apenas a renda como critério para medição do fenômeno. A maior diferença é com relação à incidência da pobreza apresentada pelo Banco Mundial que, nos anos mais recentes, ficou mais de $9 \%$ menor que a incidência registrada pelo IPM. Também é interessante comparar a pobreza extrema apresentada pelo IPEA e a pobreza severa calculada como um subgrupo da proporção de pobres cujos valores também apresentaram uma distância duas vezes maior. Estes fatos apontam para a ratificação de que a pobreza medida de forma mais robusta e abrangente, determinando melhor este fenômeno social, pode apontar um problema mais grave do que as medidas usualmente utilizadas.

Gráfico 4: Comparação entre indicadores de pobreza

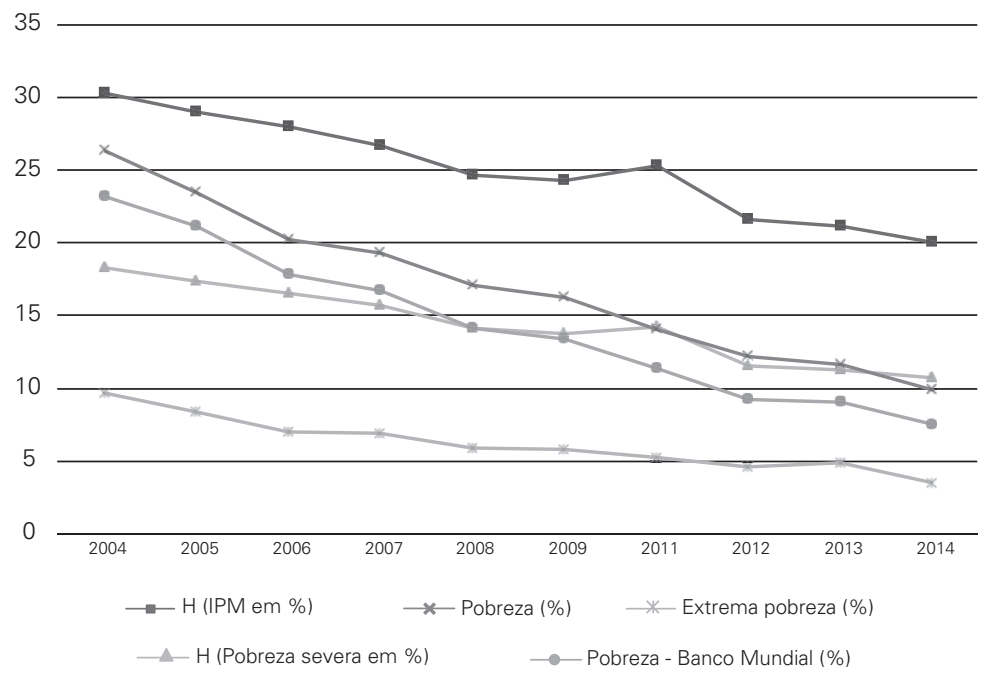

Fonte: IBGE, Microdados da PNAD 2004-2015.

Nota: Proporção de pobres do Banco Mundial está utilizando o PPP (Paridade de Poder de Compra). A linha de pobreza utilizada foi US\$3.10 por dia.

\footnotetext{
${ }^{15}$ Proporção de domicílios com renda domiciliar per capita inferior à linha de pobreza. A linha de pobreza aqui considerada é o dobro da linha de extrema pobreza, uma estimativa do valor de uma cesta de alimentos com o mínimo de calorias necessárias para suprir adequadamente uma pessoa, com base em recomendações da FAO e da OMS. Série calculada a partir das respostas à Pesquisa Nacional por Amostra de Domicílios (PNAD/IBGE).
} 
"A pobreza em massa, característica do subdesenvolvimento, tem com frequência origem numa situação de privação original do acesso à terra e à moradia. Essa situação estrutural não encontra solução através dos mecanismos dos mercados.”

Celso Furtado, em Brasil: a construção interrompida, 1992, p. 55)

Partindo-se da análise da formação histórica da economia brasileira é possível compreender como as populações de algumas regiões evoluíram criando o que foi chamado de bolsões de pobreza. Furtado (2007) mostra a dinâmica dessas economias ao longo dos séculos e este trabalho ilustrou em um mapa temático para proporção de pobres em 2010. Destacou-se que as mesmas regiões apontadas por Furtado ainda apresentam maiores proporções de pobreza. Esse quadro histórico foi o pano de fundo para os resultados deste trabalho, bem como os impactos das políticas públicas das últimas décadas, que contribuíram para melhorar as condições de vida da população. Entretanto, ainda existem desigualdades estruturais entre as grandes regiões do país, sinalizando que as ações públicas precisam continuar.

Em relação à pobreza multidimensional, houve uma redução de $37 \%$ e a população em pobreza severa apresentou uma redução de $53 \%$ no período estudado. A população vulnerável à pobreza apresentou um pequeno aumento. É possível observar uma dinâmica inversa entre incidência da pobreza multidimensional (inclusive a pobreza severa) e população vulnerável à pobreza multidimensional. Ao longo dos onze anos estudados, observa-se uma redução da população pobre e do IPM e, ao mesmo tempo, um aumento da população vulnerável à pobreza. $\mathrm{Ou}$ seja, apesar da melhoria das condições de vida da população, sair do estado de pobreza não significa que o problema esteja resolvido. Uma hipótese é que as pessoas que saíram da pobreza ficaram em situação de vulnerabilidade e as que saíram da pobreza severa ficaram na pobreza.

De forma agregada, a população abaixo da linha de pobreza multidimensional em conjunto com a população vulnerável totalizou mais de 100 milhões de pessoas no ano de 2015 , ou quase $50 \%$ da população do país.

Em termos regionais, a incidência da pobreza reduziu em todas as regiões do Brasil. Contudo, as regiões Norte e Nordeste ainda apresentam grandes contingentes populacionais em situação de pobreza multidimensional. A intensidade de pobreza apresentou resultados semelhantes para todas as regiões e sua redução também foi semelhante para todas as regiões.

A comparação da proporção de pobres do ponto de vista multidimensional com pobreza medida apenas pela renda mostra que houve uma redução nas duas. Contudo, a proporção de pessoas abaixo da linha de pobreza apresenta uma diferença entre as medidas de pobreza absoluta e o IPM. O IPM apresenta uma pro- 
porção de pobres maior, chegando a alcançar um número de aproximadamente 32 milhões de pobres em termos multidimensionais em 2015. Com as recentes mudanças do governo no Brasil e a adoção de políticas econômicas de cunho neoliberal, as perspectivas para o futuro são de deterioração dos indicadores sociais e das condições de vida da população menos favorecida.

Segundo Relatório do Banco Mundial a crise econômica (do início da década de 2010) é uma ameaça à manutenção dos avanços sociais dos últimos dez anos. O Banco Mundial fez simulações com dois cenários em 2016 e 2017: um com aumento no orçamento real do PBF e outro sem mudanças. Este cenário procura estimar o aumento no orçamento capaz de amenizar os choques da crise na pobreza até que as reformas estruturais sejam feitas no Brasil. O relatório aponta, ainda, que no cenário mais otimista teria um aumento de 2,5 milhões de pessoas pobres em 2017, e no cenário mais pessimista o aumento seria de 3,6 milhões de pessoas que vivem na situação de pobreza (Skoufias et al., 2017).

A pobreza, enquanto mazela social, é totalmente desnecessária para a humanidade, pois condena milhões de pessoas (tanto jovens quanto adultos) a uma existência aquém das possibilidades de pleno desenvolvimento humano. Uma grande parcela da população é condenada a viver na mesma condição social das gerações passadas e a ocupar papéis sociais semelhantes reproduzindo padrões de vida insatisfatórios. Enfim, a pobreza torna a sociedade mais enrijecida, pois bloqueia a mobilidade social para uma parcela considerável da população.

Considerando que ao setor privado, por natureza, não cabem objetivos sociais ex ante, pois a empresa está focada na obtenção do lucro, o combate à pobreza deve ser capitaneado pelo Estado e suas instituições. Mesmo que as externalidades positivas trazidas com redução da pobreza sejam, também, benéficas para o setor privado com o aumento do consumo. Além das políticas sociais mudanças estruturais devem ser praticadas, como a tributação progressiva que visa reduzir a brutal desigualdade (tanto de renda quanto de riqueza) que historicamente existe no Brasil. E os investimentos públicos em vários setores da economia que visam tanto à geração de renda quanto à ampliação de postos de trabalho e ocupação para as parcelas da população em condições de pobreza ${ }^{16}$.

\section{REFERÊNCIAS BIBLIOGRÁFICAS}

Alkire, S. and Foster, J. (2009) Counting and Multidimensional Poverty Measurement, OPHI Working Papers. doi: 10.1016/j.jpubeco.2010.11.006.

Alkire, S. and Santos, M. E. (2010) Acute Multidimensional Poverty: A New Index for Developing Countries.

Alkire, S. and Santos, M. E. (2013) Measuring Acute Poverty in the Developing World: Robustness and

\footnotetext{
${ }^{16}$ Com relação a possíveis trabalhos futuros pretende-se fazer uma comparação do IPM entre as áreas rural e urbana. Também pretende-se utilizar dados da PNAD Continua do IBGE e fazer uma ponderação dos pesos das dimensões mais robusta baseada em melhores critérios.
} 
Scope of the Multidimensional Poverty Index. Available at: http://www.ophi.org.uk/wp-content/ uploads/ophi-wp-59.pdf.

Codes, A. L. M. de (2008) 'A trajetória do pensamento científico sobre pobreza: em direção a uma visão complexa', pp. 1-33. Available at: http://www.ipea.gov.br/portal/index.php?option=com content\&view $=$ article $\&$ id $=4888$.

Falcão, T. and Costa, P. V. Da (2014) 'Linha de Extrema Pobreza e o Público-Alvo do Plano Brasil Sem Miséria’, O Brasil Sem Miséria, pp. 67-96. Available at: http://www.mds.gov.br/brasilsemmiseria/ Livro/artigo_2.pdf.pagespeed.ce.V7m8XDdLlH.pdf.

Fernandes, F. (2006). A Revolução Burguesa no Brasil: ensaio de interpretação sociológica. São Paulo: Ed. Globo.

Furtado, C. (2007) Formação Econômica do Brasil. São Paulo: Companhia Editora Nacional.

Gremaud, A. P. (2006) Economia Brasileira Contemporânea. SÃO PAULO: EDITORA ATLAS.

Guimarães, A. P. (1968) Quatro Séculos de Latifúndio. Rio de Janeiro: Editora Paz e Terra.

PNUD, P. D. N. U. P. O. D. (2014) Relatório do Desenvolvimento Humano 2014. Available at: http:// hdr.undp.org/sites/default/files/hdr2014_pt_web.pdf.

Rocha, S. (2013) Transferências de Renda no Brasil: O Fim da Pobreza? Rio de Janeiro: Elsevier.

Saboia, J. (2016) 'Salário Mínimo e Distribuição de Renda no Brasil a partir dos Anos 2000 Salário Mínimo e Distribuição de Renda no Brasil a partir dos Anos 2000 1'.

SEN, A. (2000) Desenvolvimento como Liberdade. São Paulo: Companhia das Letras.

Silva, L. M. O. (1996). Terras devolutas e latifúndio: efeitos da Lei de 1850. Campinas: Ed. da UNICAMP.

Skoufias, E., Nakamura, S. and Gukovas, R. M. (2017) Safeguarding against a reversal in social gains during the economic crisis in Brazil. Washington, D.C. Available at: http://documents.worldbank. org/curated/en/567101487328295113/Safeguarding-against-a-reversal-in-social-gains-during-the-economic-crisis-in-Brazil.

Soares, S. S. D. (2009) 'Metodologias para Estabelecer a Linha de Pobreza: Objetivas, Subjetivas, Relativas, Multidimensionais', p. 53. Available at: http://www.ipea.gov.br/portal/index. php?option=com_content $\&$ view=article\&id $=4933$.

Vaz, A. C. N. (2013) 'Metodologias de estimação de população em extrema pobreza: um estudo dos “Sem Declaração” e dos “Sem Rendimento” na PNAD', pp. 1-22. 